Supporting Information for:

\title{
Hydrogen Atom Transfer Reactions of Iron-Porphyrin-Imidazole Complexes as Models for Histidine-ligated Heme Reactivity
}

\author{
Jeffrey J. Warren and James M. Mayer* \\ University of Washington, Department of Chemistry, \\ Campus Box 351700, Seattle, Washington 98195
}

\section{General Experimental.}

All solutions were prepared in a nitrogen filled glovebox unless otherwise noted. Reagents were purchased from Aldrich, with the exception of DBU (Strem), mesotetraphenylporphyrin ( $\mathrm{H}_{2} \mathrm{TPP}$ ) (Strem) and iron(III) tetraphenylporphyrin chloride (Strem). meso-Tetraphenylporphyrin was purified on a basic alumina column by the method of Adler. ${ }^{1}$ 4Methylimidazole $(\mathrm{ImH})$ was purified by vacuum distillation followed by vacuum sublimation, and was stored under an inert atmosphere. TEMPOH was synthesized from TEMPO ${ }^{\circ}$ following the literature procedure. ${ }^{2}$ Tetrabutylammonium hexafluorophosphate $\left({ }^{n} \mathrm{Bu}_{4} \mathrm{NPF}_{6}\right)$ was recrystallized 3 times from absolute ethanol, and dried in vacuo for 10 hours at $100{ }^{\circ} \mathrm{C}$. DBU (1,8-diazabicyclo[5.4.0]undec-7-ene) was stored in a $\mathrm{N}_{2}$-filled glovebox and used as received. $\mathrm{Et}_{3} \mathrm{~N}$ and ${ }^{n} \mathrm{Bu}_{3} \mathrm{~N}$ were freshly distilled from $\mathrm{CaH}_{2}$, degassed and stored in a $\mathrm{N}_{2}$-filled glovebox.

Solvents were purchased from Fischer and deuterated solvents were purchased from Cambridge Isotope Labs. Acetonitrile was used as received from Burdick and Jackson (low water) and was stored in an argon pressurized stainless steel drum, plumbed directly into a glovebox. Methylene chloride, diethyl ether, pentane, toluene and benzene were dried using a "Grubbs type" Seca Solvent System installed by GlassContour. ${ }^{3}$ Methanol was dried by distilling from iodine/Mg turnings.

Instrumentation ${ }^{1} \mathrm{H}$ NMR spectra were obtained on Bruker AV300, AV301, DRX499 or AV500 spectrometers at $298 \mathrm{~K}$, unless otherwise noted. All NMR spectra of iron porphyrin derivatives were obtained on Bruker DRX499 or AV500 spectrometers. Chemical shifts are reported in ppm relative to TMS by referencing to residual solvent. UV/visible spectra were collected at ambient temperature using a Hewlett-Packard 8453 diode array spectrophotometer and are reported as $\lambda_{\max }$ in $\mathrm{nm}\left(\varepsilon, \mathrm{M}^{-1} \mathrm{~cm}^{-1}\right)$. Cyclic voltammograms were collected using an E2 Epsilon electrochemical analyzer (Bioanalytical Systems). Kinetic runs were performed on an OLIS RSM-1000 stopped-flow spectrophotometer.

(1) Adler, A. D.; Longo, F. R.; Finavells, J. D.; Goldmacher, J. A.; Korsakoff, L. J. Org. Chem. 1967, 32, 476-476.

(2) Mader, E. A.; Davidson, E. R.; Mayer, J. M. J. Am. Chem . Soc. 2007, 129, 5153-5166 (and Supporting Information).

(3) http://www.glasscontour.com 
$\mathrm{Fe}^{\text {III }}$ (TPP)Cl was synthesized by literature procedures ${ }^{4}$ and was recrystallized from 1,2dichloroethane/n-hexane. ${ }^{1} \mathrm{H}$ NMR $\left(\mathrm{CD}_{2} \mathrm{Cl}_{2}, 500 \mathrm{MHz}\right): \delta 80.53$ (s, 8H, pyrrole), 12.41 (s, 4H, $m), 11.22(\mathrm{~s}, 4 \mathrm{H}, m), 6.97(\mathrm{~s}, 4 \mathrm{H}, o), 4.21(\mathrm{~s}, 4 \mathrm{H}, p), 4.02(\mathrm{~s}, 4 \mathrm{H}, o) \mathrm{ppm}$.

$\mathbf{F e}^{\mathrm{III}}(\mathbf{T P P})(\mathbf{I m H})_{2} \mathbf{P F}_{6}$. Following Valentine et al.'s procedure for the preparation of the $\mathrm{SbF}_{6}$ salt $^{5}, \mathbf{F e} \mathbf{E}^{\text {III }}$ (TPP)CI (0.112 g, $\left.0.159 \mathrm{mmol}\right)$, silver(I) hexafluorophosphate (0.041 g, 0.163 $\mathrm{mmol})$, and 4-methylimidazole $(0.025 \mathrm{~g}, 0.305 \mathrm{mmol})$ were added to a round-bottomed flask under an inert atmosphere. Dry methylene chloride was added and the solution was stirred for 10 hours, checking periodically by UV/Vis spectrophotometry for completion. The reaction was stopped when the Fe $\mathbf{F e}^{\text {III }}$ (TPP)Cl visible bands had disappeared completely. The precipitated $\mathrm{AgCl}$ was removed. The solvent was removed under vacuum and the resulting solid was dissolved in approximately $5 \mathrm{~mL}$ of fresh methylene chloride. Slightly less than an equal volume of toluene was added and the reaction was cooled to $-20{ }^{\circ} \mathrm{C}$ overnight, during which time purple crystals formed. The resulting crystals were filtered and dried under vacuum for several hours to give $0.140 \mathrm{~g}$ of $\mathbf{F e}^{\mathrm{III}}(\mathbf{T P P})(\mathbf{I m H})_{2} \mathbf{P F}_{\mathbf{6}}(90 \%)$. ${ }^{1} \mathrm{H} \mathrm{NMR}\left(\mathrm{CD}_{2} \mathrm{Cl}_{2}, 500 \mathrm{MHz}\right): \delta 13.08$ (s, 6H, Im$\left.\mathrm{CH}_{3}\right), 10.78$ (s, 2H, Im-CH), 8.27 (s, 2H, Im-NH), 6.43 (s, 4H, p), $6.25(\mathrm{~s}, 8 \mathrm{H}, o / m), 4.93$ (s, 8H, $o / m),-12.55(\mathrm{~s}, 2 \mathrm{H}, \mathrm{Im}-\mathrm{CH}),-17.23$ (s, 8H, pyrrole) ppm. UV/Vis (MeCN) 548 (9800). Anal. Calcd. for $\mathrm{C}_{52} \mathrm{H}_{40} \mathrm{~F}_{6} \mathrm{FeN}_{8} \mathrm{P}: \mathrm{C}, 63.88 ; \mathrm{H}, 4.13 ; \mathrm{N}, 11.46$. Found: C, 63.56; H, 4.13; N, 11.45 .

Fe $^{\text {II }}(\mathbf{T P P})(\mathrm{ImH})_{2}$. Following Collman, ${ }^{6} \mathrm{Fe}^{\mathrm{III}}(\mathbf{T P P})$ was generated from $\mathbf{F e}^{\mathrm{III}}(\mathbf{T P P}) \mathbf{C l}$ $(0.055 \mathrm{~g}, 0.078 \mathrm{mmol})$ and $\mathrm{Cr}^{\mathrm{II}}(\mathrm{acac})_{2}(0.087 \mathrm{~g}, 0.506 \mathrm{mmol}$; acac = acetylacetonate $)$. The solids were added to a swivel frit under an inert atmosphere. Benzene $(\sim 10 \mathrm{~mL})$ was vacuum transferred from $\mathrm{Na}^{0} / \mathrm{ketyl}$. The reaction mixture was warmed to room temperature and stirred for 15 minutes. The solution was filtered and the solids were washed with refluxing benzene. The purple $\mathrm{Fe}^{\mathrm{II}}$ (TPP) was added a benzene solution containing 4-methylimidazole $(0.014 \mathrm{~g}$, $0.171 \mathrm{mmol}$ ) and pink solids precipitated upon stirring. Washing with diethyl ether and drying under vacuum yielded $0.05 \mathrm{~g}(78 \%)$ of pink $\mathbf{F e}^{\mathrm{II}}(\mathbf{T P P})(\mathbf{I m H})_{2} \cdot{ }^{1} \mathrm{H}$ NMR $\left(50 \% \mathrm{DMSO}_{\mathrm{d} 6} /\right.$ $50 \% \mathrm{CD}_{3} \mathrm{CN}$ with $\left.5 \mathrm{mM} \mathrm{ImH}, 500 \mathrm{MHz}, 270 \mathrm{~K}\right) \delta 11.63$ (s, 8H, pyrrole), 9.61 (s, 2H, Im-CH), $8.50(\mathrm{~s}, 2 \mathrm{H}, \mathrm{Im}-\mathrm{CH}), 7.95(\mathrm{~s}, 8 \mathrm{H}, o), 7.63(\mathrm{~s}, 12 \mathrm{H}, m+p), 0.678\left(\mathrm{~s}, 6 \mathrm{H}, \mathrm{Im}_{-} \mathrm{CH}_{3}\right) \mathrm{ppm}$. UV-Vis (MeCN) 533 (18000), 565 (9000). Anal. Calcd. for $\mathrm{C}_{52} \mathrm{H}_{40} \mathrm{FeN}_{8} \bullet 1 / 2 \mathrm{C}_{6} \mathrm{H}_{6}: \mathrm{C}, 75.86 ; \mathrm{H}, 4.86$; N, 12.87. Found: C, 75.40; H, 4.95; N, 12.27.

$\mathbf{F e}^{\text {III }} \mathbf{T P P}(\operatorname{Im})(\operatorname{ImH})$. Using a similar procedure to that of Valentine and co-workers ${ }^{5}$ $\mathbf{F e}^{\mathrm{III}} \mathbf{I m}$ was generated in situ using base in the presence of $5 \mathrm{mM}$ ImH. UV-Vis (MeCN) 552 (8300).

$\mathbf{F e}^{\mathrm{II}} \mathbf{T P P}(\mathrm{Im})(\mathbf{I m H}) . \quad \mathbf{F e}^{\mathrm{II}} \mathbf{I m}^{-}$was generated in situ using a large excess (>500 equivalents) of DBU in the presence of $10 \mathrm{mM} \mathrm{ImH.} \mathrm{UV-Vis} \mathrm{(MeCN)} 536$ (18000), 566 (11000), 600 (shoulder, 6000).

${ }^{n} \mathbf{B u}_{4}$ NAscH. 5,6-Isopropylidene-L-ascorbic acid $\left.\left(\mathrm{H}_{2} \mathrm{Asc}\right) 0.516 \mathrm{~g}, 2.4 \mathrm{mmol}\right)$ was dissolved in $10 \mathrm{~mL}$ dry methanol in a two neck flask. Under flowing nitrogen, $2.5 \mathrm{~mL}{ }^{n} \mathrm{Bu}_{4} \mathrm{NOH}$ ( $1 \mathrm{M}$ in $\mathrm{MeOH}, 0.3 \mathrm{mmol}$ ) was added slowly to the reaction mixture. The solution slowly turned pale yellow. Solvent was removed under vacuum to give a yellow oil. $\mathrm{Et}_{2} \mathrm{O}$ was vacuum

(4) Niño, M.; Giraldo, M. E.; Páez-Mozo, E. A. J. Mol. Catal. A: Chem. 2001, 139-151.

(5) Quinn, R.; Nappa, M.; Valentine, J. S. J. Am. Chem. Soc. 1982, 104, 2588-2595.

(6) Collman, J. P.; Reed, C. A. J. Am. Chem. Soc. 1973, 95, 2048-2049. 
transferred onto the oil and removed, 3 times, to give a pale yellow solid $(1.0 \mathrm{~g}, 80 \%)$. The UV spectrum in MeCN shows a peak at $275 \mathrm{~nm}\left(\varepsilon=13000 \mathrm{M}^{-1} \mathrm{~cm}^{-1}\right)$, close to the reported spectrum for $\mathrm{AscH}^{-}$in 0.05 aqueous phosphate buffer, $\mathrm{pH} 5.5 .{ }^{7}{ }^{1} \mathrm{H} \mathrm{NMR}\left(\mathrm{CD}_{3} \mathrm{CN}, 500 \mathrm{MHz}\right) \delta 4.03(\mathrm{~m}$, $3 \mathrm{H}$, methylene), $3.13\left(\mathrm{~m}, 8 \mathrm{H},{ }^{n} \mathrm{Bu}-\mathrm{CH}_{2}\right), 1.63\left(\mathrm{~m}, 8 \mathrm{H},{ }^{n} \mathrm{Bu}-\mathrm{CH}_{2}\right), 1.38\left(\mathrm{~m}, 14 \mathrm{H},{ }^{n} \mathrm{Bu}-\mathrm{CH}_{2}+\right.$ isopropylidne- $\left.\mathrm{CH}_{3}\right), 1.00$ (t, $\left.12 \mathrm{H},{ }^{n} \mathrm{Bu}_{-} \mathrm{CH}_{3}\right)$ ppm. To identify the resonances for the isopropylidene group, which are obscured by the ${ }^{n} \mathrm{Bu}_{4} \mathrm{~N}^{+}$, [DBU-H]AscH was generated from $\mathrm{DBU}+\mathrm{H}_{2} \mathrm{Asc}$ in $\mathrm{CD}_{3} \mathrm{CN} .{ }^{1} \mathrm{H}$ NMR $\left.\left(\mathrm{CD}_{3} \mathrm{CN}, 300 \mathrm{MHz}, \mathrm{DBU}-\mathrm{H}^{+} \mathrm{AscH}\right)^{-}\right) \delta 4.03(\mathrm{~m}, 3 \mathrm{H}$, methylene), $3.48\left(\mathrm{~m}, 2 \mathrm{H}, \mathrm{DBUH}^{+}\right), 3.43\left(\mathrm{t}, 2 \mathrm{H}, \mathrm{DBUH}^{+}\right), 3.29\left(\mathrm{t}, 2 \mathrm{H}, \mathrm{DBUH}^{+}\right), 2.68(\mathrm{~m}, 2 \mathrm{H}$, $\left.\mathrm{DBUH}^{+}\right), 1.94\left(\mathrm{~m}, 2 \mathrm{H}, \mathrm{DBUH}^{+}\right), 1.66\left(\mathrm{~m}, 6 \mathrm{H}, \mathrm{DBUH}^{+}\right), 1.32\left(\mathrm{~s}, 3 \mathrm{H},-\mathrm{CH}_{3}\right), 1.28\left(2,3 \mathrm{H},-\mathrm{CH}_{3}\right)$ ppm.

Titrations with $\mathbf{D B U}$ and $\mathbf{N R}_{\mathbf{3}}\left(\mathbf{R}=\mathbf{E t}\right.$ or $\left.{ }^{n} \mathbf{B u}\right)$. All solutions were prepared under an inert atmosphere and used within 1 hour of preparation. Measurements were made at ambient temperature $(295 \mathrm{~K})$. Cuvettes were filled under an inert atmosphere and capped with a PTFE/Silicone coated septum (SpectroCell, USA). A fresh septum was used for each titration. Solutions of $\sim 8 \times 10^{-5} \mathrm{M} \mathbf{F e}^{\mathrm{III}} \mathbf{I m H}$ were titrated with 0.1 equivalent additions of DBU. Titrations with $\mathrm{NR}_{3}$ were carried out in a similar manner, but with 5 equivalent additions.

Titrations of $5 \times 10^{-5} \mathbf{M} \mathbf{F} \mathbf{e}^{\mathbf{I I}} \mathbf{I m H}$ and DBU were conducted using quartz cuvettes with Kontes Teflon ${ }^{\mathrm{TM}}$ stoppers. Six quartz cuvettes were charged with $3 \mathrm{~mL} \mathrm{Fe}{ }^{\mathrm{II}}$ stock solution. An aliquot (10-100 eq) of a concentrated DBU solution was placed above each Teflon ${ }^{\mathrm{TM}}$ stopper and the apparatus was capped with a rubber septum. Initial UV/Vis spectra were taken for each cuvette, then reactions were initiated by opening the Teflon ${ }^{\mathrm{TM}}$ stopper and mixing the two solutions. Solutions were allowed to equilibrate for $\sim 1$ minute before measurement.

Electrochemistry. Electrochemical measurements were performed in a $\mathrm{N}_{2}$ filled glovebox with approximately $3 \mathrm{mM}$ substrate and $0.1 \mathrm{M}{ }^{n} \mathrm{Bu}_{4} \mathrm{NPF}_{6}$ in acetonitrile. $\mathrm{CV}$ measurements of all iron compounds were conducted in $5 \mathrm{mM} \mathrm{ImH}$. The electrodes used were: working electrode, glassy carbon; reference electrode, $\mathrm{Ag}^{0} / \mathrm{AgNO}_{3}$ in electrolyte solution; and auxiliary electrode, platinum wire. All potentials are referenced versus internal ferrocene standard. The estimated errors are $\pm 0.010 \mathrm{~V}$. Scans were taken at 25 and $100 \mathrm{mV} \mathrm{s}^{-1}$ in the absence of ferrocene. Ferrocene was added and CVs were obtained at 25 and $100 \mathrm{mV} \mathrm{s}^{-1}$, with no change in peak currents or potentials. A typical CV is shown in Figure S1.

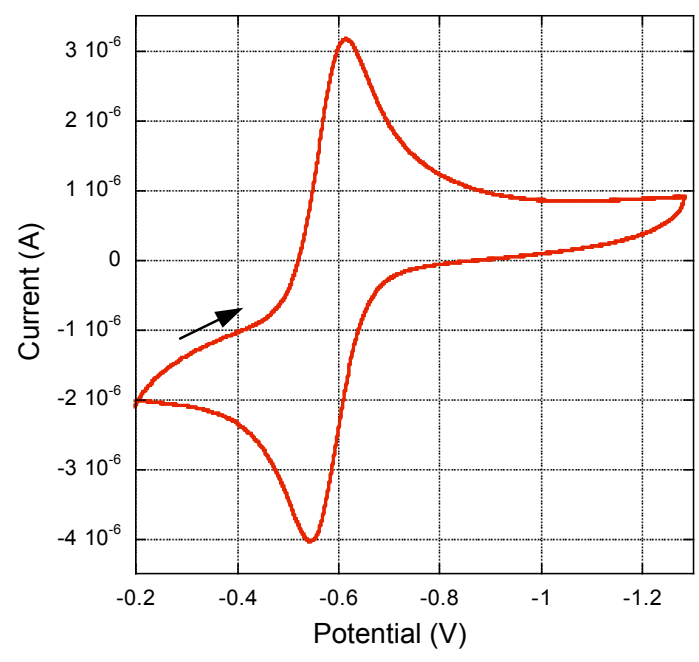

Figure S1: Cyclic voltammogram of $\mathbf{F e}^{\mathrm{II}} \mathrm{ImH}$ in acetonitrile (potential in $\mathrm{V} v s$. $\mathrm{Cp}_{2} \mathrm{Fe}^{+/ 0}$ ), arrow indicates scan direction, scan rate was $100 \mathrm{mV} \mathrm{s}^{-1}$.

(7) Cabral, J.; Haake, P. J. Org. Chem. 1988, 53, 5742-5750. 
Stopped-flow kinetics, General. All solutions used for kinetics were prepared in a $\mathrm{N}_{2}$ filled glovebox. The stopped-flow syringes were loaded in the glovebox, and removed one at a time for each respective kinetic run. Measurements were at $295 \mathrm{~K}$ unless otherwise indicated. For reactions at temperatures other than $295 \mathrm{~K}$, all solutions were allowed to equilibrate in the water bath of the stopped-flow instrument for $5 \mathrm{~min}$.

Stopped-flow kinetics for $\mathrm{Fe}^{\mathrm{III}} \mathrm{Im}+{ }^{n} \mathrm{Bu}_{4} \mathrm{NHAsc}$ (Hydrogen Atom Transfer, Figs. S2, S4). $\mathbf{F e}^{\mathbf{I I I}} \mathbf{I m}$ (in $\mathrm{CH}_{3} \mathrm{CN}, 5 \mathrm{mM}$ ImH) was freshly generated from $\mathbf{F e} \mathbf{e}^{\mathrm{III}} \mathbf{I m H}$ and 1 equivalent of DBU. $k_{1}$ was measured using 1-2 equivalents of ${ }^{n} \mathrm{Bu}_{4}$ NHAsc. The reaction of $9 \mu \mathrm{M} \mathrm{Fe} \mathbf{~ e}^{\mathrm{III}} \mathbf{I m}$ and 10.5 $\mu \mathrm{M}^{n} \mathrm{Bu}_{4} \mathrm{NHAsc}$ was $(45 \pm 5) \%$ complete in the dead time of our stopped-flow spectrometer (2-4 $\mathrm{ms}$ ). This was determined from the first spectrum using the known extinction coefficients of $\mathrm{Fe}^{\mathrm{III}} \mathbf{I m}$ and $\mathrm{Fe}^{\mathrm{II}} \mathbf{I m H}$. [The reaction of DAsc ${ }^{-}$is slower and more of the reaction is observed, Figure S4A below.] For the kinetic analysis, this spectrum was set as time $=0$, with starting concentrations of $5 \mu \mathrm{M} \mathbf{F e}^{\mathrm{III}} \mathbf{I m}$ and $6.5 \mu \mathrm{M}^{n} \mathrm{Bu}_{4} \mathrm{NHAsc}$. The data and kinetic fit are shown in Figure S2. Figure S2(B) also indicates the absorbance expected prior to any reaction, by the horizontal (black) bar around $\mathrm{t}=0$. The data were fit by the SPECFIT/32 ${ }^{\mathrm{TM}}$ global analysis program $^{8}$ to a simple second-order kinetic model (blue curved line in Figure 2 (B)). The quality of the fit was high, based on the good agreement of the SPECFIT-calculated component spectra for $\mathbf{F e}^{\text {III }} \mathbf{I m}$ and $\mathbf{F e} \mathbf{e}^{\mathrm{II}} \mathbf{I m H}$ with the known spectra. Different reactions at varying initial concentrations all gave the same second-order rate constant $k_{1}=(3.5 \pm 0.9) \times 10^{7} \mathrm{M}^{-1} \mathrm{~s}^{-1}$ within error.
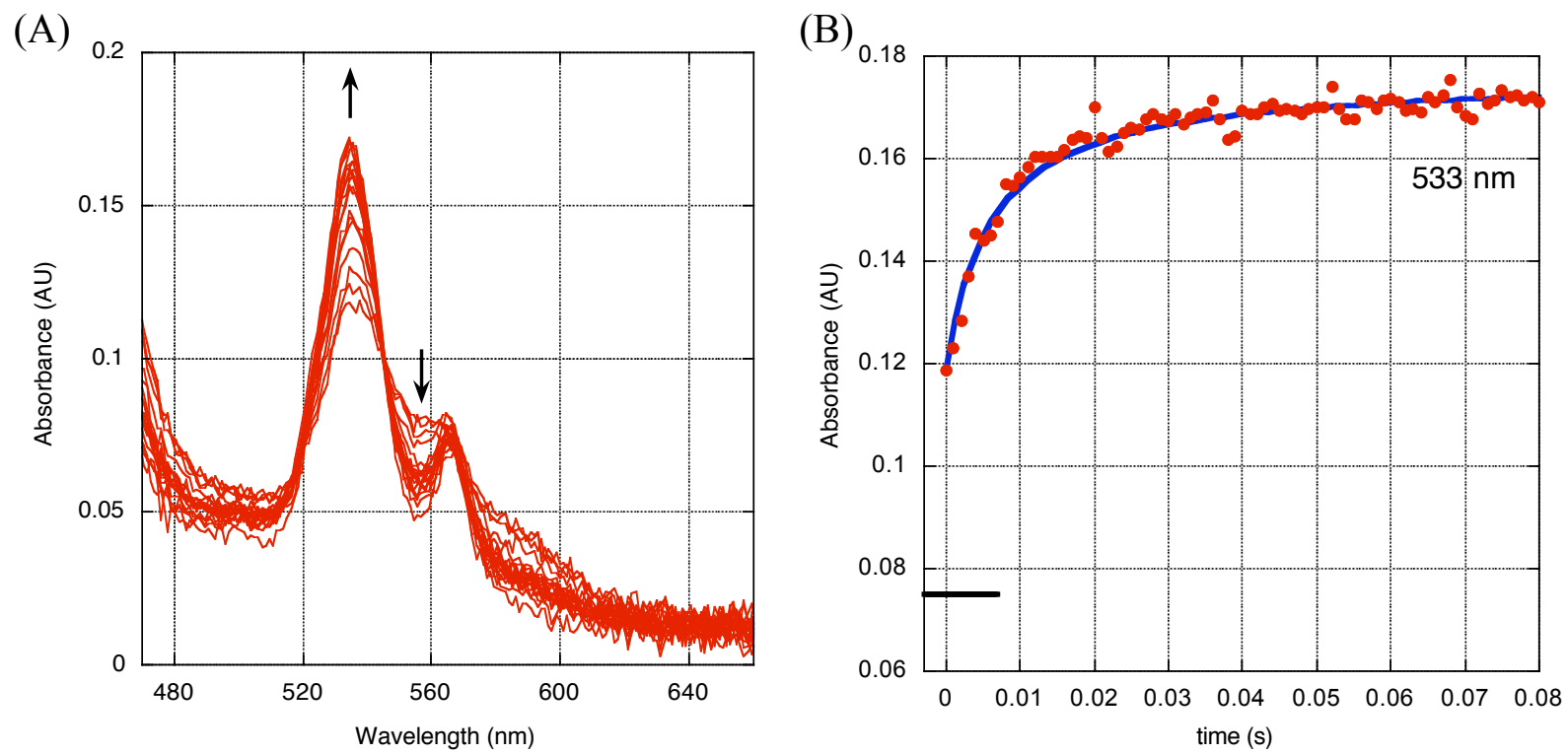

Figure S2: (A) UV/Vis spectra for reaction between $9 \mu \mathrm{M} \mathbf{F e}^{\mathrm{III}} \mathbf{I m}$ and $10.5 \mu \mathrm{M}{ }^{n} \mathrm{Bu}_{4} \mathrm{NHAsc}$ over the course of $0.08 \mathrm{~s}$. The reaction was $(45 \pm 5) \%$ complete within the mixing time of the stopped-flow. (B) Trace at $533 \mathrm{~nm}$ of the data (red 0 ) and fit resulting from analysis with SPECFIT/32 using the second-order kinetic model described above (blue - - ). The absorbance expected prior to any reaction is indicated by the horizontal (black) bar around time $=0$, which was set to be the time of the first spectrum after complete mixing.

(8) Binstead, R. A.; Zuberbühler, A. D.; Jung, B. Specfit, Version 3.0.38 (32-bit Windows); Spectrum Software Associates: Chapel Hill, NC, 2006. 
Reaction between $\mathrm{Fe}^{\mathrm{III}} \mathrm{ImH}$ and ${ }^{n} \mathrm{Bu}_{4} \mathrm{NAscH}$ (Electron Transfer, Figure S3). Reactions between $\mathbf{F e}^{\text {IIII } I m H}$ and ${ }^{n} \mathrm{Bu}_{4} \mathrm{NAscH}$ were conducted with a 1:1 or 1:2 molar ratio in $\mathrm{MeCN}$ in the presence of $5 \mathrm{mM} 4$-methylimidzole, following the procedure described above. Figure S3 shows a representative dataset (blue dots, lower points) and a comparison with the related HAT reaction between $\mathbf{F e}^{\text {III }} \mathbf{I m}$ and ${ }^{n} \mathbf{B u}_{4} \mathbf{N A s c H}$ (red dots, upper points). The kinetic data were analyzed with SPECFIT/32. The data are not well described by a second-order kinetic model, suggesting a more complex reaction mechanism. This may involve deprotonation or disproportionation reaction(s) of HAsc ${ }^{\circ}$, or trace base deprotonating some $\mathbf{F e}^{\mathbf{I I I}} \mathbf{I m H}$. The poor second-order fit yields an apparent rate constant of $2 \times 10^{6} \mathrm{M}^{-1} \mathrm{~s}^{-1}$ but this can only be considered a rough estimate. That the (HAT) reaction of $\mathbf{F e}^{\mathbf{I I I}} \mathbf{I m}+{ }^{n} \mathrm{Bu}_{4} \mathrm{NAscH}$ is ten times faster than the (ET) reaction of $\mathbf{F e}^{\mathrm{III}} \mathbf{I m H}+{ }^{n} \mathbf{B u}_{4} \mathbf{N A s c H}$ is evident from the raw data (Figure S3) as well as this approximate second-order fitting.

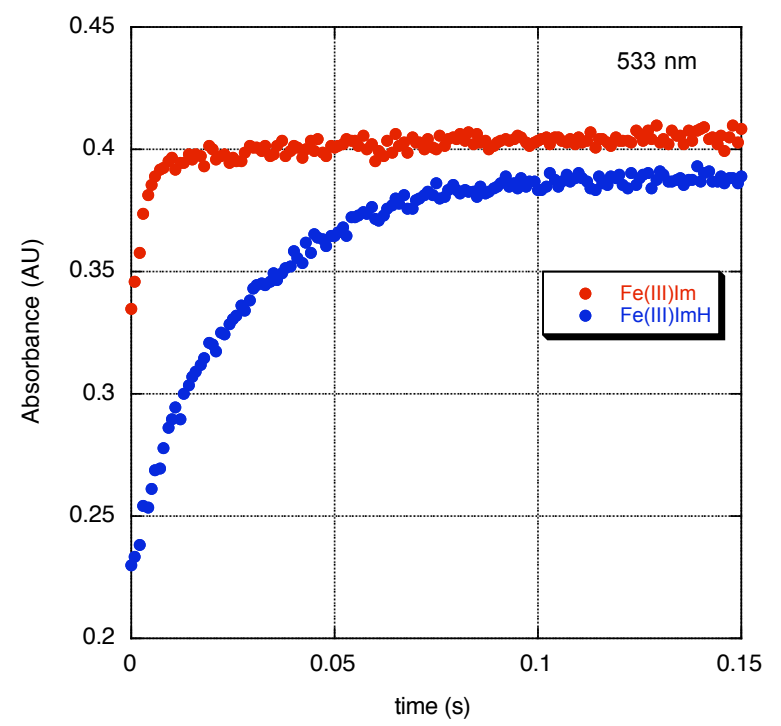

Figure S3: Comparison of the reactions of $30 \mu \mathrm{M}^{n} \mathrm{Bu}_{4} \mathrm{NAscH}$ with $25 \mu \mathrm{M}$ Fe ${ }^{\mathrm{III}} \mathbf{I m}$ (red dots, upper) and $25 \mu \mathrm{M}$ Fe $\mathbf{e}^{\text {III }} \mathbf{I m H}$ (blue dots, lower); only the absorbance at $533 \mathrm{~nm}$ is shown. Static UV/Vis measurement shows that $\mathbf{F e}^{\mathbf{I I I}} \mathbf{I m}$ and $\mathbf{F e} \mathbf{~}^{\text {III }} \mathbf{I m H}$ have similar starting absorbances at 533 $\mathrm{nm}$ (0.235 AU at this concentration). Significant reaction of $\mathbf{F e}^{\mathrm{III}} \mathbf{I m}$ and ${ }^{n} \mathrm{Bu}_{4} \mathrm{NAscH}$ occurs in the mixing time of the stopped-flow spectrometer at these concentrations; "time $=0$ " is the time of the first spectrum after complete mixing. 
Kinetic Isotope Effect (KIE) Measurements (Figure S4). Measurements of rates for deuterium transfer from $\mathrm{AscD}^{-}$were performed as described above except that $5 \mathrm{mM}$ 4methylimidazole-D ( $\mathrm{ImD}$ ) was used (Figure S4, at right). The isotope effect of electron transfer reaction $\left(\mathbf{F e}^{\mathrm{III}} \mathbf{I m H}+{ }^{n} \mathrm{Bu}_{4} \mathrm{NAscH}\right)$ was also measured under these conditions (Figure S4, at left). ImD was prepared by stirring freshly sublimed $\mathrm{ImH}$ with $\mathrm{CH}_{3} \mathrm{OD}$ under an inert atmosphere. $\mathrm{MeOH} / \mathrm{MeOD}$ was removed under vacuum and fresh $\mathrm{MeOD}$ was vacuum transferred onto the $\mathrm{ImH} / \mathrm{D}$ three times. After the third addition the solvent was removed and the product was sublimed. The deuterium enrichment was found to be $(95 \pm 10) \%$ by ${ }^{1} \mathrm{H}$ NMR in dry $\mathrm{CD}_{3} \mathrm{CN}$. At these concentrations, the proteo reaction was $(65 \pm 5) \%$ complete at the time of the first spectrum while the deutero reaction was $(30 \pm 5) \%$ complete.
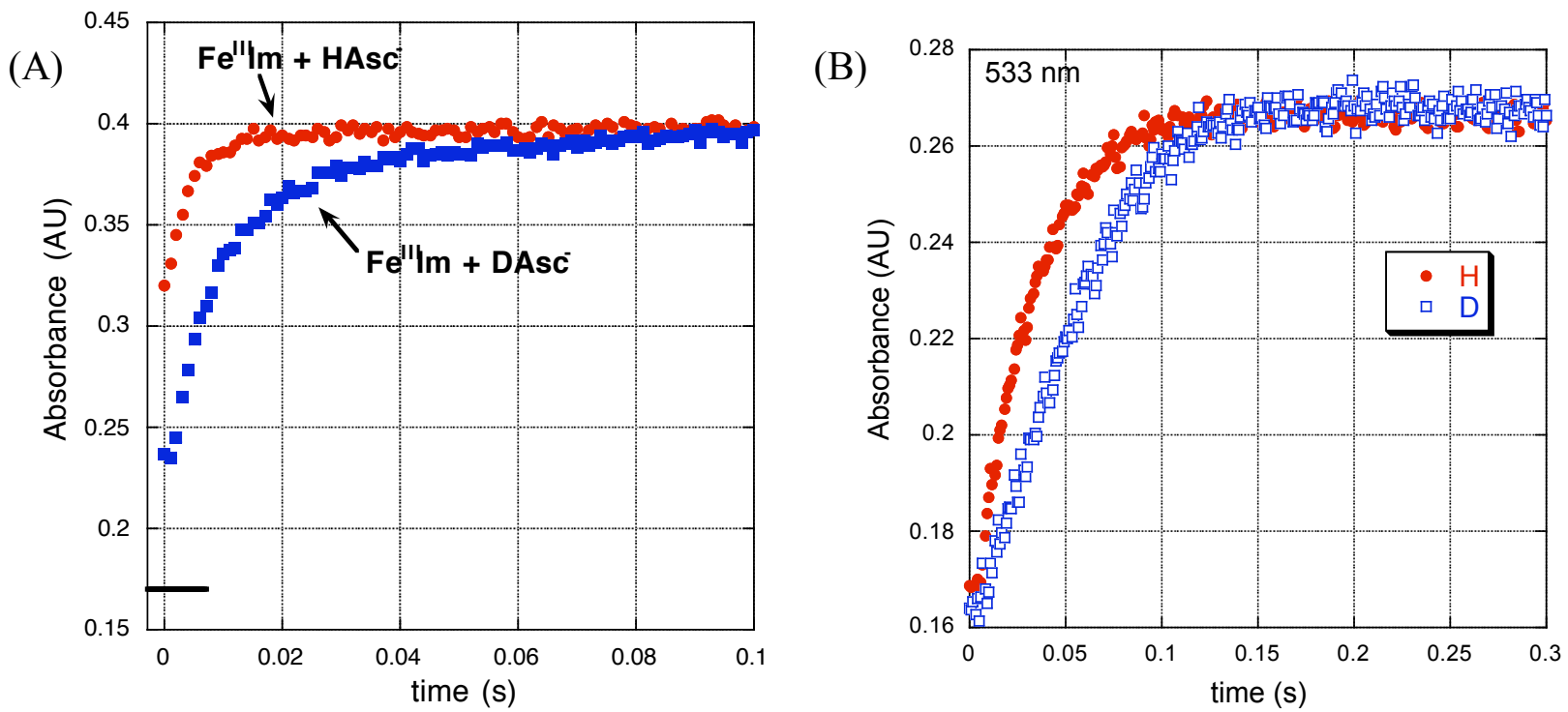

Figure S4: (A) Kinetic traces at $533 \mathrm{~nm}$ for the reactions between $23 \mu \mathrm{M} \mathrm{Fe} \mathbf{~}^{\mathrm{III}} \mathbf{I m}$ and either 23 $\mu \mathrm{M} \mathrm{HAsc}{ }^{-}$(red circles, 0 ) or $23 \mu \mathrm{M} \mathrm{DAsc}^{-}$(blue squares, $\square$ ). Significant reaction occurs within the mixing time of the instrument. From static UV/Vis measurements, both proteo and deutero samples have the same starting absorbance, as indicated by the black line near time $=0$, which was set to be the time of the first spectrum after complete mixing. (B) Comparison of kinetic traces at $533 \mathrm{~nm}$ for reaction of $\mathbf{F e}^{\mathbf{I I I}} \mathbf{I m H}+{ }^{n} \mathrm{Bu}_{4} \mathrm{NAscH}$ (red circles, O) and $\mathbf{F e} \mathbf{e}^{\mathbf{I I I}} \mathbf{I m D}+$ ${ }^{n} \mathrm{Bu}_{4} \mathrm{NascD}$ (blue squares, $\square$ ). Neither data set is well described by a simple second-order kinetic model, suggesting that the reactions proceed via more complex mechanism(s). The poor fits of the data do not allow the determination of an accurate KIE.

Stopped-Flow Kinetics for reactions with TEMPO or TEMPOH (Figures S5, S6). Solutions were prepared and kinetic runs were conducted in the same manner as above. $k_{4}$ was measured using 1-5 equivalents (mixed second order approach to equilibrium) or 10-15 equivalents (pseudo-first order) of TEMPOH. The reverse rate constant $k_{-3}$ was measured using 10-100 equivalents of TEMPO (pseudo-first order approach to equilibrium). 
(A)

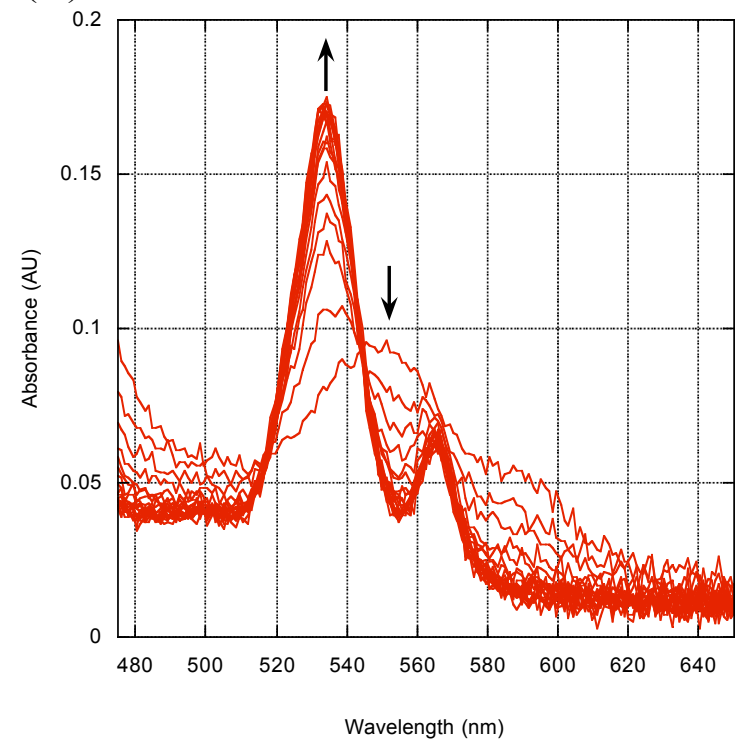

(B)

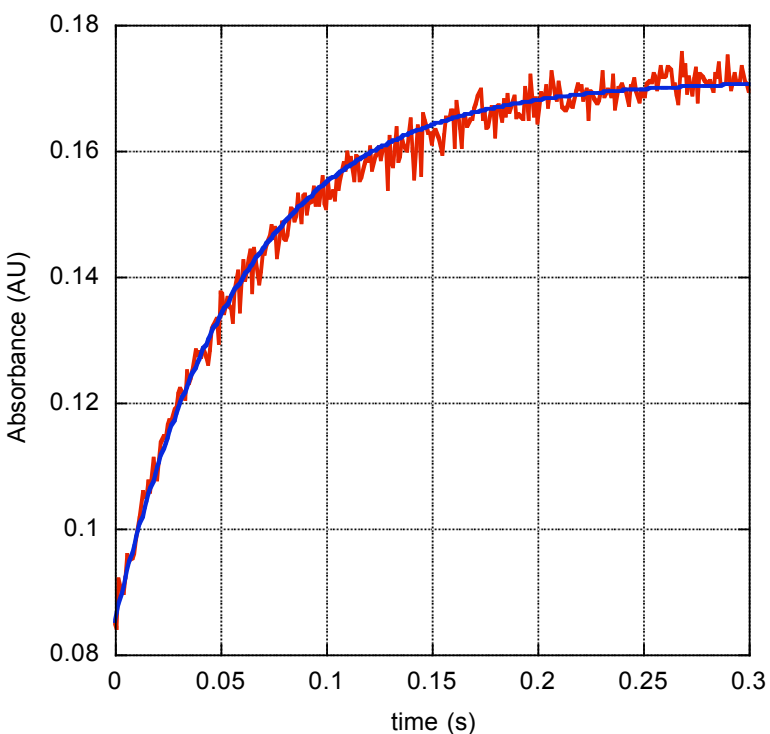

Figure S5: Kinetic data for the reaction of $1.1 \times 10^{-5} \mathrm{M} \mathrm{Fe}^{\mathrm{III}} \mathbf{I m}$ and $1.9 \times 10^{-4} \mathrm{TEMPOH}$ (pseudo-first order conditions). (A) UV/Vis spectra over the course of $0.3 \mathrm{~s}$. (B) Trace at 533 $\mathrm{nm}$ of the data (red noisy line -) and fit resulting from analysis with SPECFIT/32 using firstorder kinetic model (blue smooth line-).
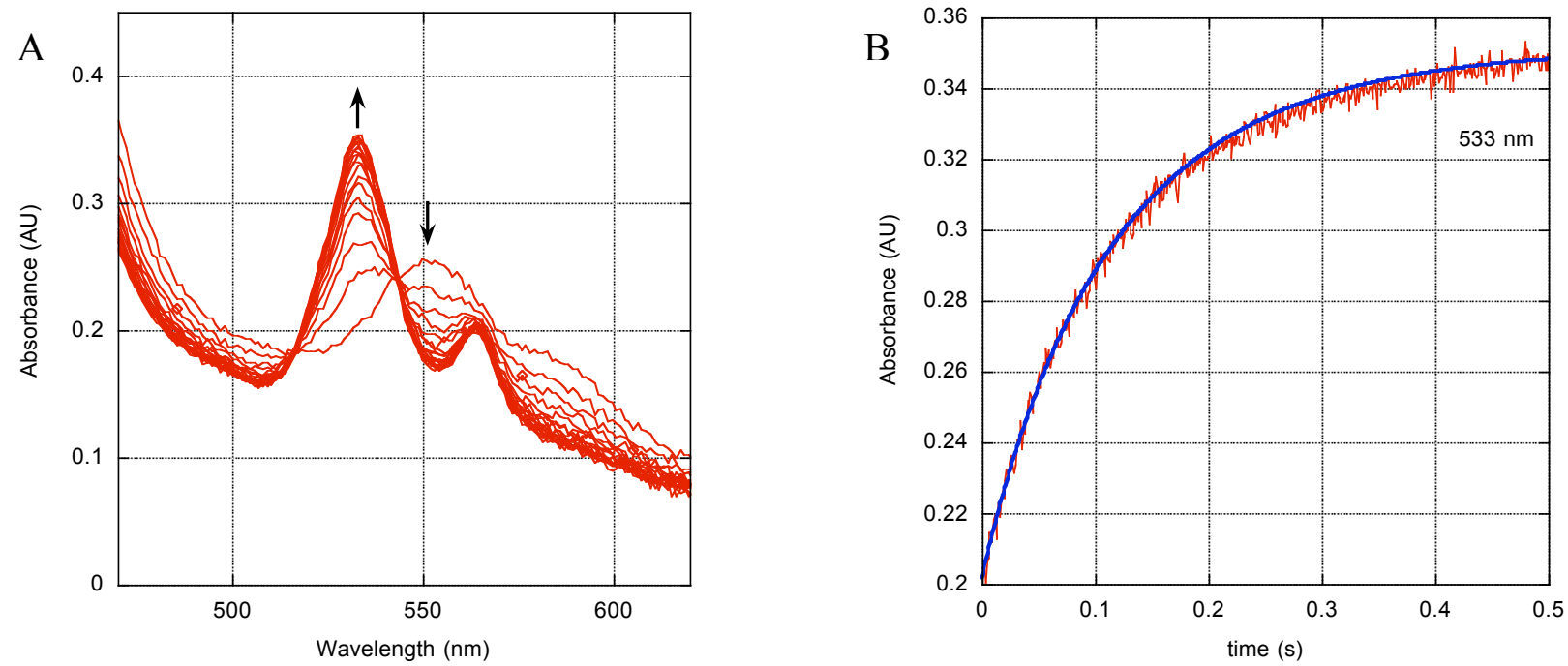

Figure S6: Kinetic data for the reaction of $2.5 \times 10^{-5} \mathrm{M} \mathrm{Fe}^{\mathbf{I I I}} \mathbf{I m}$ and $1.0 \times 10^{-4} \mathrm{M}$ TEMPOH (mixed second-order conditions). (A) UV/Vis spectra over the course of $0.6 \mathrm{~s}$. (B) Trace at 533 $\mathrm{nm}$ of the data (red noisy line - ) and fit resulting from analysis with SPECFIT/32 using a second-order approach to equilibrium kinetic model ( blue smooth line - $)$ ). 
(A)

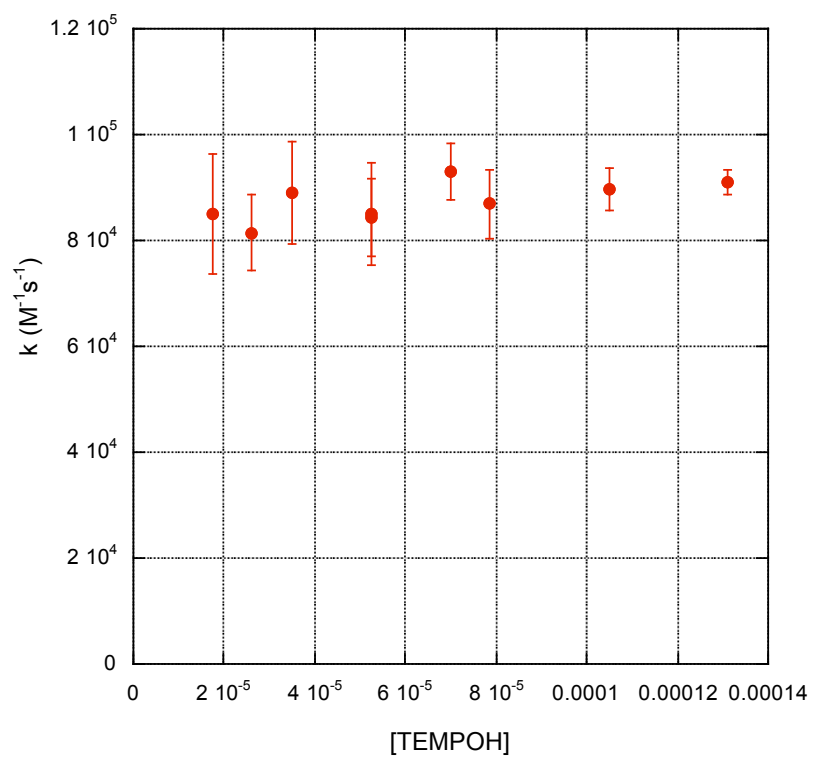

(B)

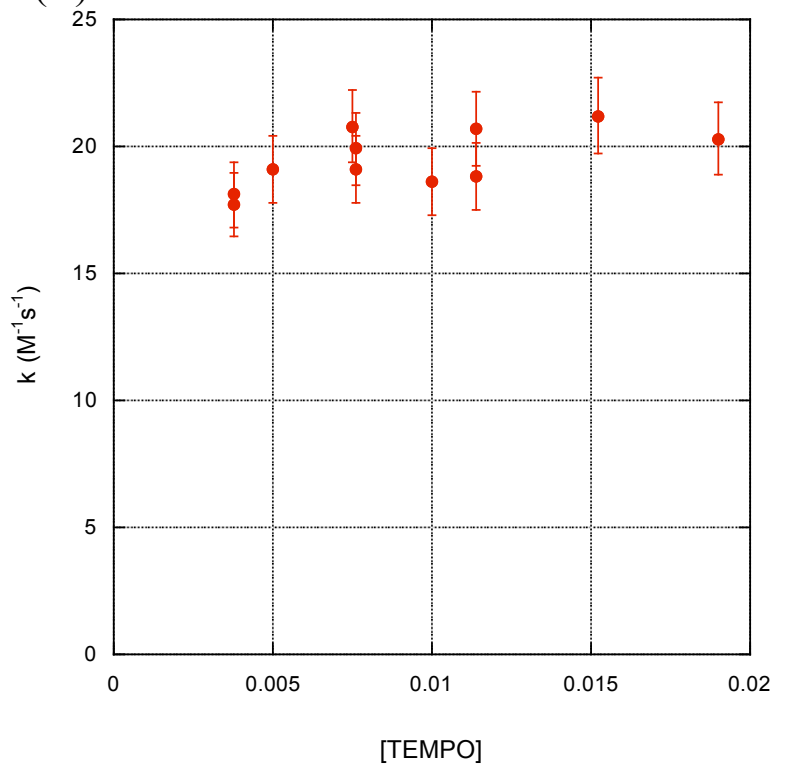

Figure S7: Second-order rate constants for: (A) Fe ${ }^{\text {III }} \mathbf{I m}+$ TEMPOH $\left(k_{4}\right)$ as a function of [TEMPOH] and (B) Fe ${ }^{\text {II }} \mathbf{I m H}+$ TEMPO $\left(k_{-4}\right)$ as a function of [TEMPO].

$\mathbf{p} \boldsymbol{K}_{\mathrm{a}}$ and $\boldsymbol{E}^{\circ}$ values for TEMPOH. $E^{\circ}\left(\mathrm{TEMPOH}^{\circ+0}\right)$ in acetonitrile vs. $\mathrm{AgNO}_{3} / \mathrm{Ag}^{0}$ was reported by Semmelhack and co-workers. ${ }^{9}$ The $\mathrm{p} K_{\mathrm{a}}$ OF TEMPOH in DMSO was reported by Bordwell and co-workers; ${ }^{10}$ the $\mathrm{p} K_{\mathrm{a}}$ in acetonitrile was estimated from this value following the method of Chantooni and co-workers. ${ }^{11}$

(9) Semmelhack, M. F.; Chou, C. S.; Cortes, D. A. J. Am. Chem. Soc. 1983, 105, 4492-4494.

(10) Bordwell, F. G.; Liu, W.-Z. J. Am. Chem. Soc. 1996, 118, 10819-10823.

(11) Chantooni, M. K., Jr.; Kolthoff, I. M. J. Phys. Chem. 1976, 80, 1306-1310. 
Measurement of the $\mathrm{Fe}^{\mathrm{II}} \mathrm{ImH}+$ Benzoquinone Equilibrium Constant (K, Figure S8). In an inert atmosphere glove box, $3 \mathrm{~mL}$ aliquots of a $5 \times 10^{-5} \mathrm{M}$ stock solution of $\mathbf{F e} \mathbf{~}^{\mathrm{II}} \mathbf{I m H}$ at $295 \mathrm{~K}$ were placed in 5 quartz cuvettes with Kontes Teflon ${ }^{\mathrm{TM}}$ stoppers. An aliquot (10-500 eq) of a concentrated benzoquinone solution was placed above each Teflon ${ }^{\mathrm{TM}}$ stopper and the apparatus was capped with a rubber septum. Initial UV/Vis spectra were taken for each cuvette, then reactions were initiated by opening the Teflon ${ }^{\mathrm{TM}}$ stopper and mixing the two solutions. Solutions were allowed to equilibrate for $\sim 15$ seconds before measurement.

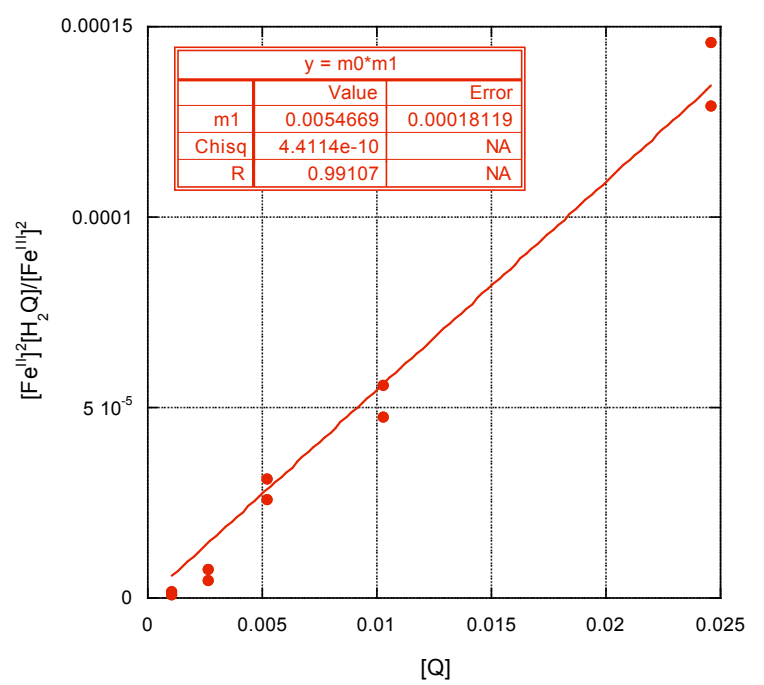

Figure S8: Plot of $\left[\mathbf{F e}^{\mathrm{II}} \mathbf{I m H}\right]^{2}[$ hydroquinone $] /\left[\mathbf{F e}^{\mathrm{III}} \mathbf{I m}\right]^{2}$ vs. [benzoquinone]. The [hydroquinone] was taken to be equal to $0.5\left[\mathrm{Fe}^{\mathrm{III}} \mathbf{I m}\right]$. The slope gives the value of $K_{2}$.

Measurement of the $\mathrm{Fe}^{\mathrm{III}} \mathrm{Im}+\mathrm{TEMPOH}$ Equilibrium Constant ( $K_{4}$, Figure S9). In an inert atmosphere, $3 \mathrm{~mL}$ aliquots of a $5 \times 10^{-5} \mathrm{M}$ stock solution of $\mathbf{F e}^{\text {II }} \mathbf{I m H}$ were placed in 8 quartz cuvettes with Kontes Teflon ${ }^{\mathrm{TM}}$ stoppers at $295 \mathrm{~K}$. An aliquot (10-500 eq) of a concentrated TEMPO solution was placed above each Teflon ${ }^{\mathrm{TM}}$ stopper and the apparatus was capped with a rubber septum. Initial $\mathrm{UV} / \mathrm{Vis}$ spectra were taken for each cuvette, then reactions were initiated by opening the Teflon ${ }^{\mathrm{TM}}$ stopper and mixing the two solutions. Solutions were allowed to equilibrate for $\sim 1$ minute before measurement.

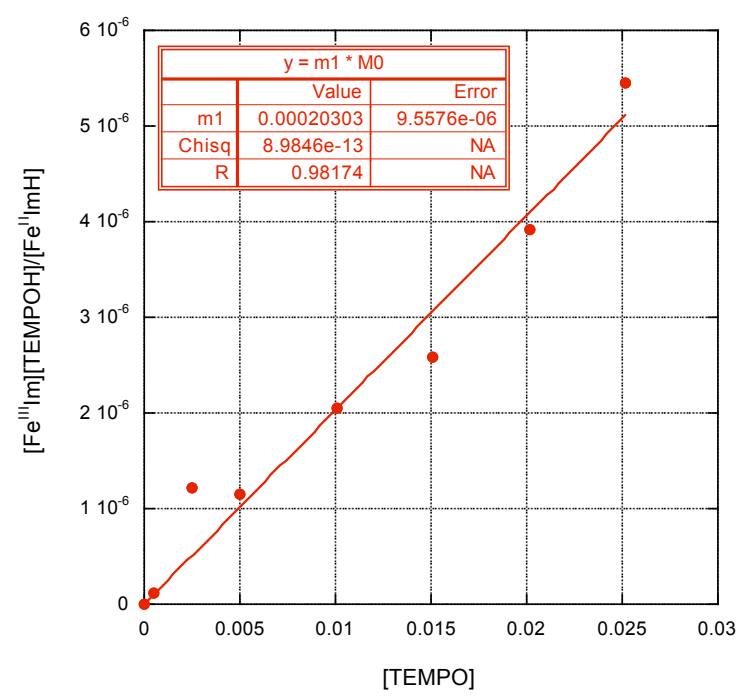

Figure S9: Plot of $\left[\mathbf{F e}^{\text {III }} \mathbf{I m}\right][$ TEMPOH $] /\left[\mathbf{F e}^{\text {II }} \mathbf{I m H}\right]$ vs. [TEMPO]. The $[\mathrm{TEMPOH}]$ was taken to be equal to $\left[\mathrm{Fe}^{\mathrm{II}} \mathbf{I m H}\right]$. The slope gives the value of $\mathrm{K}_{4}{ }^{-1}$. 
van't Hoff analysis of the $\mathrm{Fe}^{\mathrm{II}} \mathrm{ImH}+$ TEMPO Equilibrium Constant $\left(K_{4}\right.$, Figure S10). Equilibrium constants were measured as a function of temperature analogously to the measurement of $K_{4}$ above. Solutions were allowed to temperature equilibrate for 10 minutes in a thermostated 8-cell holder before mixing. New solutions were used at each temperature. van't Hoff analysis yields $\Delta H^{\circ}{ }_{4}=$ $-13.0 \pm 1.0 \mathrm{kcal} \mathrm{mol}^{-1}, \Delta S_{3}^{\circ}=-27 \pm 3 \mathrm{cal} \mathrm{K}^{-1}$ $\mathrm{mol}^{-1}$, and $\Delta G^{\circ}{ }_{3}=-5.0 \pm 1.3 \mathrm{kcal} \mathrm{mol}^{-1}$, in good agreement with static UV/Vis measurements and the ratio of $k_{4} / k_{-4}$.

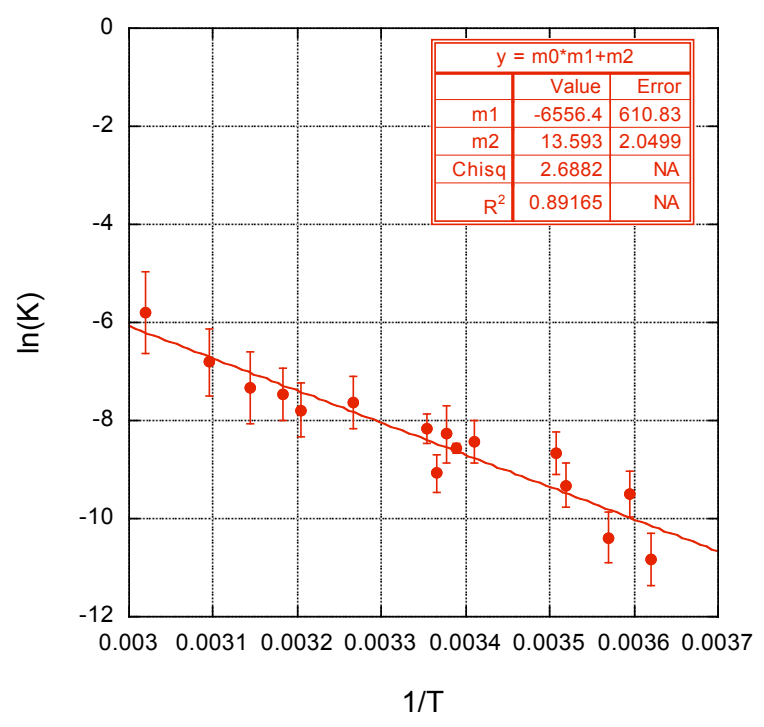

Figure S10: van't Hoff plot for the reaction of Fe II ImH with TEMPO. Note that this is the opposite of reaction 4, so this is a plot of $\ln \left(K_{4}{ }^{-1}\right)$ vs. $\mathrm{T}^{-1}$ and the slope is $-\Delta H^{\circ}{ }_{4}$.

\section{Thermochemistry of hydroquinone.}

Scheme S1.

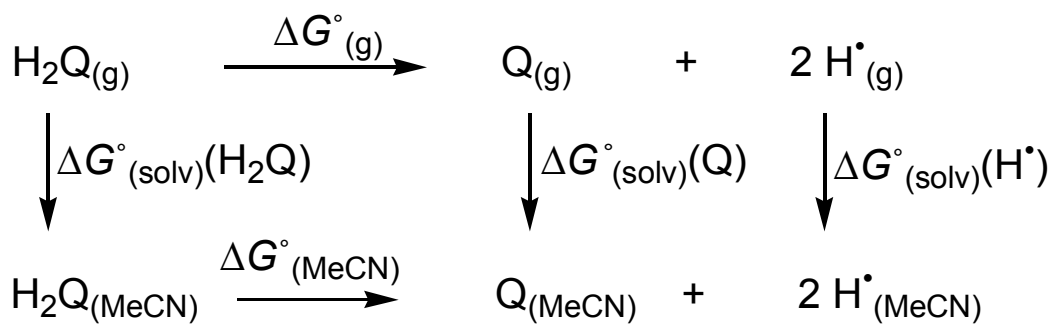

- $\Delta G_{(\mathrm{g})}{ }^{\circ}$ from gas phase enthalpies and entropies of formation: ${ }^{12}$

hydroquinone $\left(\mathrm{H}_{2} \mathrm{Q}\right): \Delta H_{f}^{\circ}(\mathrm{g})=-66.2 \pm 0.33 \mathrm{kcal} \mathrm{mol}^{-1}, \mathrm{~S}_{f}^{\circ}(\mathrm{g})=82 \pm 1.2$ e.u.

benzoquinone $(\mathrm{Q}): \Delta H_{f}^{\circ}(\mathrm{g})=-29 \pm 1 \mathrm{kcal} \mathrm{mol}^{-1}, \mathrm{~S}_{f}^{\circ}(\mathrm{g})=79.6$ e.u. (error not given) ${ }^{13}$

hydrogen atom $\left(\mathrm{H}^{\circ}\right): \Delta H_{f}^{\circ}(\mathrm{g})=52.1 \pm 0.001 \mathrm{kcal} \mathrm{mol}^{-1}, \mathrm{~S}_{f^{\circ}(\mathrm{g})}^{\circ}=27.419 \pm 0.0005$ e.u.

(12) All values from NIST Chemistry WebBook (http://webbook.nist.gov/chemistry), Accessed 10, October 2007, except as noted.

(13) $\mathrm{S}_{f}^{\circ}(\mathrm{g})$ (benzoquinone): Burcat, A.; Ruscic, B. “Third Millennial Ideal Gas and Condensed Phase Thermochemical Database for Combustion with Updates from Active Thermochemical Tables" ftp://ftp.technion.ac.il/pub/supported/aetdd/thermodynamics (accessed 15 July 2007). 
The above data give $\Delta G_{(\mathrm{g})}{ }^{\circ}=125.8 \pm 1.1 \mathrm{kcal} \mathrm{mol}^{-1}$. This value is the sum of the two gasphase BDFEs. Therefore the average of the two gas phase BDFEs for $\mathrm{H}_{2} \mathrm{Q}=62.9 \pm 0.55$ kcal $\mathrm{mol}^{-1}$.

- Free Energies of Solvation:

The sum of the two $\mathrm{H}_{2} \mathrm{Q}$ BDFEs in MeCN solution is given by (see Scheme $\mathrm{S} 1$ above):

$$
\Delta G_{(\mathrm{MeCN})}^{\circ}=\Delta G_{(\mathrm{g})}^{\circ}-\Delta G_{(\text {solv })}^{\circ}\left(\mathrm{H}_{2} \mathrm{Q}\right)+\Delta G_{(\text {solv })}^{\circ}(\mathrm{Q})+2 \Delta G_{(\text {solv })}^{\circ}\left(\mathrm{H}^{\circ}\right)
$$

\section{Solvation of $\mathrm{H}^{\bullet}$ in $\mathrm{CH}_{3} \mathrm{CN}$ :}

Roduner has shown that the free energy of solvation of $\mathrm{H}^{*}$ in $\mathrm{CH}_{3} \mathrm{CN}$ is well approximated by the free energy of solvation of $\mathrm{H}_{2}{ }^{14} \Delta H_{\text {solv }}{ }^{\circ}\left(\mathrm{H}_{2}\right)=1.56 \pm 0.02 \mathrm{kcal} \mathrm{mol}^{-1}$ and $\Delta S_{\text {solv }}{ }^{\circ}\left(\mathrm{H}_{2}\right)=-11.92$ cal $\mathrm{K}^{-1} \mathrm{~mol}^{-1}{ }^{15}$ [No error was reported for $\Delta S_{\text {solv }}{ }^{\circ}\left(\mathrm{H}_{2}\right)$; we have assumed a $1.3 \%$ error $( \pm 0.15 \mathrm{cal}$ $\left.\mathrm{K}^{-1} \mathrm{~mol}^{-1}\right)$ equal to the $\%$ error in $\Delta H_{\text {solv }}{ }^{\circ}\left(\mathrm{H}_{2}\right)$.] These data give $\Delta G_{\text {solv }}{ }^{\circ}\left(\mathrm{H}_{2}\right)=5.11 \pm 0.05 \mathrm{kcal}$ $\mathrm{mol}^{-1}$ which is taken to be equal to $\Delta G_{\text {solv }}{ }^{\circ}\left(\mathrm{H}^{\circ}\right)$.

\section{Differential Solvation of $\mathrm{H}_{2} \mathrm{Q}$ and $\mathrm{Q}$ in $\mathrm{CH}_{3} \mathrm{CN}$ :}

There has been extensive discussion of the difference in solvation enthalpies of phenols and phenoxyl radicals, in the context of phenol solution BDEs. ${ }^{16,17}$ Ingold et al. ${ }^{16}$ have argued that the primary contributor to this difference is the strength of the hydrogen bond in the phenol, which they estimate using Abraham's parametric approach ${ }^{18}$ to be typically $\sim-1 \mathrm{kcal} \mathrm{mol}^{-1}$ in $\mathrm{MeCN}$. More complete theoretical treatments give values of -1 to $-3 \mathrm{kcal} \mathrm{mol}^{-1}$. $^{17}$ The difference in free energies of solvation has not been examined, however, nor are we aware of any estimates of the differential solvation of hydroquinone vs. benzoquinone in MeCN. Phenol and phenoxyl are much more polar than $\mathrm{H}_{2} \mathrm{Q}$ and $\mathrm{Q}$, suggesting that the free energies of solvation for $\mathrm{H}_{2} \mathrm{Q}$ and $\mathrm{Q}$ are significantly smaller than those for phenol and phenoxyl. On that basis, we estimate that $\Delta G^{\circ}{ }_{(\text {solv })}\left(\mathrm{H}_{2} \mathrm{Q}\right)-\Delta G^{\circ}{ }_{(\text {solv })}(\mathrm{Q}) \cong-2 \pm 2 \mathrm{kcal} \mathrm{mol}^{-1}$.

3. Therefore, the free energy in solution is (Scheme 1):

$$
\begin{aligned}
\Delta G_{(\mathrm{MeCN})}^{\circ} & =\Delta G_{(\mathrm{g})}^{\circ}-\left[\Delta G_{(\text {solv })}^{\circ}\left(\mathrm{H}_{2} \mathrm{Q}\right)-\Delta G_{(\text {solv })}^{\circ}(\mathrm{HQ})\right]+2 \Delta G_{(\text {solv })}^{\circ}\left(\mathrm{H}^{\circ}\right) \\
& =\left(125.8 \pm 1.1 \mathrm{kcal} \mathrm{mol}^{-1}\right)-\left[-2 \pm 2 \mathrm{kcal} \mathrm{mol}^{-1}\right]+2\left(5.11 \pm 0.05 \mathrm{kcal} \mathrm{mol}^{-1}\right)
\end{aligned}
$$

(14) (a) Roduner, E. Radiat. Phys. Chem. 2005, 72, 201-206. (b) Tilset, M. Electron Transfer in Chemistry; Balzani, V.; Ed.; Organic Molecules, Organometallic and Inorganic Molecules, 2; Wiley VCH: Weinheim, Germany, 2001; pp 677-713.

(15) Brunner, E. J. Chem. Eng Data 1985, 30, 269-273.

(16) Mulder, P.; Korth, H.-G.; Pratt, D. A.; DiLabio, G. A.; Valgimigli, L.; Pedulli, G. F.; Ingold, K. U. J. Phys. Chem. A 2005, 109, 2467-2655.

(17) Borges dos Santos, R. M.; Cabral, B. J. C.; Simões, J. A. M. Pure Appl. Chem. 2007, 79, 1369-1382.

(18) Abraham, M. H.; Grellier, P. L.; Prior, D. V.; Duce, P. P.; Morris, J. J.; Taylor, P. J. J. Chem. Soc. Perkin Trans. 2 1989, 699-711. 


$$
=138.0 \pm 2.3 \mathrm{kcal} \mathrm{mol}^{-1}
$$

We conservatively conclude that the average BDFE for $\mathrm{H}_{2} \mathrm{Q}$ in $\mathrm{MeCN}$ is $69 \pm 2 \mathrm{kcal} \mathrm{mol}^{-1}$. As noted in the text, this value is consistent with the other thermochemical data reported: the $K_{2}$ for $2 \mathbf{F e}^{\mathrm{III}} \mathbf{I m}+\mathrm{H}_{2} \mathrm{Q} \rightleftharpoons 2 \mathbf{F e}^{\mathrm{II}} \mathbf{I m H}+\mathrm{Q}$; the $K_{4}$ for $\mathbf{F e}{ }^{\mathrm{III}} \mathbf{I m}+\mathrm{TEMPOH} \rightleftharpoons \mathbf{F e}^{\mathrm{II}} \mathbf{I m H}+$ TEMPO; and the independently determined BDFEs for TEMPOH and $\mathbf{F e} \mathbf{e}^{\mathrm{II}} \mathbf{I m H}$. 